\title{
ТЕХНОЛОГИЯ КОМБИНИРОВАННОГО ЛАЗЕРНОГО ЛЕЧЕНИЯ ЭПИРЕТИНАЛЬНОГО ФИБРОЗА: ФИЗИКО-МАТЕМАТИЧЕСКАЯ МОДЕЛЬ
}

\author{
Х. П. Тахчиди ${ }^{1,2}$, Г. И. Желтов ${ }^{4}$, Г. Ф. Качалина ${ }^{2}$, Т. А. Касмынина ${ }^{2}$, Е. П. Тебина ${ }^{3}$
}

1 Российский национальный исследовательский медицинский университет имени Н. И. Пирогова, Москва, Россия

${ }^{2}$ Научно-исследовательский центр остальмологии, Российский национальный исследовательский медицинский университет имени Н. И. Пирогова, Москва, Россия

${ }^{3}$ Педиатрический факультет, Российский национальный исследовательский медицинский университет имени Н. И. Пирогова, Москва, Россия

${ }^{4}$ Институт физики имени Б. И. Степанова НАН Беларуси, Минск, Беларусь

\begin{abstract}
Эпиретинальная мембрана (ЭРМ) возникает в результате пролиферативно-дистрофического процесса во внутренних слоях сетчатки и витреомакулярном интерфейсе. Особый интерес в лечении витреоретинальной патологии представляет применение лазерного излучения в макулярной зоне. При адекватном выборе режимов облучения (длины волны, длительности экспозиции и мощности излучения) лечебный эффект достигается при минимальном повреждающем действии на структуры сенсорной сетчатки. Этот фактор явился серьезным стимулом для развития и совершенствования лазерных технологий в лечении ЭРМ. В представленной работе проведен анализ биофизического отклика структурных элементов сетчатки (динамики температурных и акустических полей, термоденатурации, стимуляции репаративных процессов) при последовательном воздействии лазерного квазинепрерывного излучения и серии микроимпульсов с дальнейшей оценкой основных механизмов лечебного эффекта разработанной комбинированной лазерной технологии у пациентов с ЭРМ.
\end{abstract}

Ключевые слова: эпиретинальный фиброз, субпороговое микроимпульсное лазерное воздействие, комбинированная лазерная технология, оптическая когерентная томография

Информация о вкладе авторов: Х. П. Тахчиди, Г. Ф. Качалина - концепция и дизайн исследования; Е. П. Тебина - сбор и обработка материала; Т. А. Касмынина - лазерное лечение пациента; Г. И. Желтов, Т. А. Касмынина, Е. П. Тебина — написание текста; Г. И. Желтов, Х. П. Тахчиди редактирование

Соблюдение этических стандартов: исследование одобрено этическим комитетом РНИМУ имени Н. И. Пирогова (протокол № 160 от 19 декабря 2016 г.).

Для корреспонденции: Екатерина Павловна Тебина

Волоколамское шоссе, д. 30, корп. 2, 123182; ekaterinatebina@mail.ru

Статья получена: 01.03.2019 Статья принята к печати: 15.03.2019 Опубликована онлайн: 30.04.2019

DOI: $10.24075 /$ vrgmu.2019.032

\section{COMBINATION LASER THERAPY FOR EPIRETINAL MEMBRANE: A PHYSICO-MATHEMATICAL MODEL}

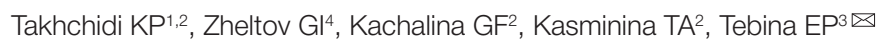

${ }^{1}$ Pirogov Russian National Research Medical University, Moscow, Russia

2 Research Center for Ophthalmology, Pirogov Russian National Research Medical University, Moscow, Russia

${ }^{3}$ Faculty of Pediatrics, Pirogov Russian National Research Medical University, Moscow, Russia

${ }^{4}$ Stepanov Institute of Physics, Minsk, Belarus

An epiretinal membrane (ERM) is a product of abnormal cell proliferation on the inner surface of the retina and at the vitreomacular interface. Laser therapy is an interesting modality for treating pathologies of the vitreomacular interface. The wise choice of laser settings (wavelength, exposure time, power) minimizes damage to the retina and ensures a good therapeutic effect. This could be a serious impetus to the development and refinement of laser technologies for treating ERM. This work investigates the biophysical response of structural retinal components, including the dynamics of temperatures and acoustic oscillations, protein denaturation, and stimulation of tissue regeneration, to a quasi-cw laser beam and a subsequent series of laser micropulses. The manuscript also analyzes the mechanisms underlying the therapeutic effect of the proposed laser therapy in patients with ERM.

Keywords: epiretinal membrane, subthreshold micropulse laser photocoagulation, combination laser therapy, optical coherence tomography

Author contribution: Takhchidi KP and Kachalina GF conceived and designed the study; Tebina EP collected and analyzed the data; Kasminina TA performed laser therapy; Zheltov GI, Kasminina TA, and Tebina EP wrote the manuscript; Zheltov Gl and Takhchidi KP revised the manuscript.

Compliance with ethical standards: the study was approved by Russian National Research Medical University (Protocol № 160 of December 19, 2016).

$\triangle$ Correspondence should be addressed: Ekaterina P. Tebina

Volokolamskoe shosse 30, bld. 2, 123182; ekaterinatebina@mail.ru

Received: 01.03.2019 Accepted: 15.03.2019 Published online: 30.04.2019

DOI: 10.24075/brsmu.2019.032

Ежегодно среди глазной патологии, приводящей к слабовидению и слепоте, все чаще встречаются фиброзные заболевания сетчатки, которыми страдают миллионы людей во всем мире [1]. Эпиретинальная мембрана (ЭРМ) является результатом пролиферативнодистрофического процесса во внутренних слоях сетчатки и витреомакулярном интерфейсе [2]. Он проявляется путем формирования на ретинальной поверхности соединительнотканной структуры, обладающей контрактильными свойствами, вызывая складчатость сетчатки с последующим формированием макулярного отверстия [2, 3].

Наиболее значительную роль в возникновении ЭРМ отводят: задней отслойке стекловидного тела (ЗОСТ), структурным анатомическим особенностям внутренней пограничной мембраны (ВПМ) наличию микропор и нарушениям микроциркуляции капиллярного русла макулярной зоны [4-6]. По данным мировых исследований, в состав ЭРМ входят разные типы клеток: глиальные клетки (ретинальные клетки 
Мюллера, астроциты и микроглия), гиалоциты, макрофаги, ретинальный пигментный эпителий (РПЭ) и фибробласть [7-8]. Независимо от происхождения исходных клеточных компонентов, ключевым моментом в процессе формирования и прогрессирования ЭРМ является их трансдифференцировка в миофибробластоподобные клетки, для которых характерно выраженное продуцирование трансформирующего фактора роста коллагена, что способствует сокращению ЭРМ [9-10]. Показано, что самая активная клеточная пролиферация при ЭРМ происходит в толще сетчатки задолго до появления клинических симптомов. После возникновения мембраны на ретинальной поверхности процесс пролиферации завершается [11].

Существует большое количество различных методов подавления клеточной пролиферации на ранних стадиях развития: интравитреальное введение высоких доз глюкокортикостероидов, лучевая терапия и применение цитостатиков [12]. Однако предложенные методы несут довольно высокий риск развития нежелательных побочных явлений и не зарекомендовали себя в лечении данной патологии. На сегодняшний день основные принципь ведения пациентов с ЭРМ сводят к двум аспектам: динамическому наблюдению за пролисреративным процессом и витреоретинальной хирургии [13].

Несмотря на значительный прогресс в изучении патогенетических механизмов развития ЭРМ, условия трансдифференцировки витреоретинальных клеток в миофибробласты не изучены. Нерешенным остается вопрос, стоит ли применять удаление ЭРМ хирургическим путем на этапе ее начального развития, или же оперативное вмешательство можно отложить до тех пор, пока не появятся характерные для нее клинические симптомы (снижение остроты зрения, метаморфопсии). Тем не менее добиться функционального успеха после проведения оперативного вмешательства удается далеко не всегда, при этом зачастую ЭРМ является реккурентной [12].

Особый интерес в лечении патологии витреоретинального интерфейса представляет применение лазерного излучения в макулярной зоне [14-15]. При адекватном выборе режимов облучения (длина волны, длительность экспозиции и мощность излучения) лечебный эффект можно достигнуть при минимальном повреждающем действии на структуры сенсорной сетчатки [16-17]. Одним из последних достижений в рассматриваемой области является запатентованная и прошедшая первичную клиническую апробацию методика комбинированного лазерного лечения начальных стадий эпиретинального фиброза, которая включает избирательную точечную коагуляцию сетчатки в зоне ЭРМ желтым лазером и последующую субпороговую стимуляцию сериями микроимпульсов [18]. Результатом лечебного воздействия являются инволюция ЭРМ, улучшение остроты зрения, повышение светочувствительности сетчатки.

Дальнейшее применение и развитие предложенной методики во многом зависит от понимания механизмов ее лечебного воздействия. Первым шагом в решении этой задачи является углубленное изучение биосизических процессов взаимодействия излучения с отдельными структурными элементами сетчатки. Здесь, в частности, может быть использован метод математического моделирования, адаптированный к режимам лечебного воздействия на ЭРМ [17-20].

Нами была создана физико-математическая модель, позволившая прогнозировать биофизические эффекты применяемых параметров лазерного воздействия на

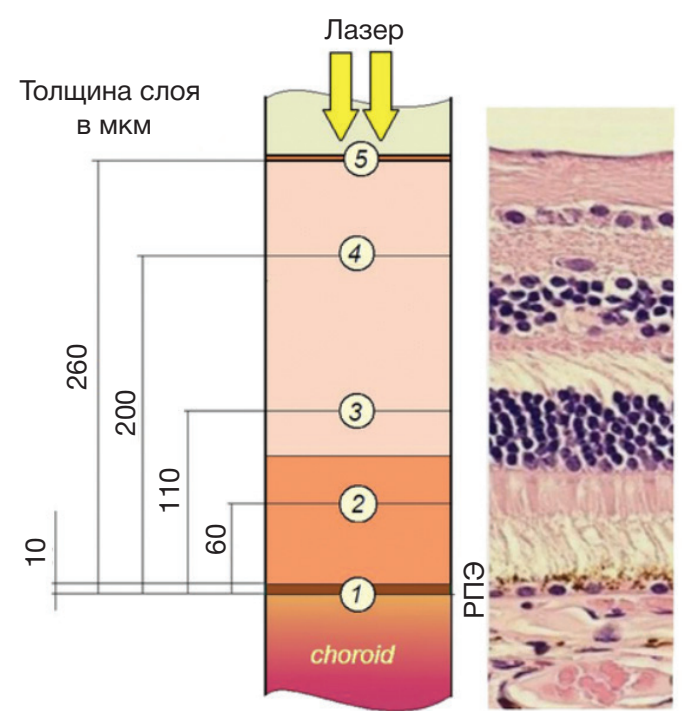

Рис. 1. Анатомо-топографическая структура модели хориоретинального комплекса. 1 - ретинально-пигментный эпителий (10 мкм), 2 фоторецепторный слой (60 мкм), 3 - наружный зернистый слой (110 мкм), 4 - внутренний зернистый слой (200 мкм), 5 - внутренняя пограничная мембрана (260 мкм)

ткани пациентов. Целью данного исследования являлся анализ биофизического отклика структурных элементов сетчатки (динамики температурных и акустических полей, термоденатурации, стимуляции репаративных процессов) при последовательном воздействии лазерного квазинепрерывного излучения и серии микроимпульсов.

\section{МАТЕРИАЛЫ И МЕТОДЫ}

Основываясь на результатах исследований, проведенных на моделях животных (кролики, приматы), были определены условия и механизмы формирования локальных первичных изменений нативной структуры тканей хориоретинального комплекса под воздействием лазерного излучения [17, 19].

Эти представления в совокупности с данными об оптикоспектральных и физических свойствах интраокулярных структур послужили базой для разработки физической модели взаимодействия потоков лазерного излучения с тканями глазного дна (рис. 1) [19]. Математическая интерпретация этой модели положена в основу расчетов и оптимизации параметров излучения, необходимых для стабилизации ретинальной архитектоники и ингибирования клеточной пролиферации на ранних стадиях развития ЭРМ.

Модель представляет собой многослойную систему, где геометрические размеры, физические и оптические свойства слоев равнозначны свойствам основных анатомических структур глазного дна [21]. В наиболее

$\rho(Z) \operatorname{Cp}(Z) \frac{\partial T}{\partial t}+F^{(k)}(U, V)=\frac{1}{r} \frac{\partial}{\partial r}\left[r \mathcal{X}(Z) \frac{\partial T}{\partial r}\right]+\frac{\partial}{\partial Z}\left[\mathcal{H}(Z) \frac{\partial T}{\partial Z}\right]+Q(t) q(r, Z, k, s) ;$

$$
q_{i}(r, Z)=\frac{E_{i-1}\left(k_{i}+s_{i}\right) R_{i-1}^{2}}{r_{i-1}^{2}} \exp \left[-k_{i}\left(Z-Z_{i}\right)-\frac{r^{2}}{r_{s}^{2}}\right]
$$

Рис. 2. Уравнение теплообмена для каждого слоя: $i$ - номер слоя $T(r, Z, t)$ - превышение температуры над физиологической нормой $\left(37^{\circ} \mathrm{C}\right)$; Сp (Z), p (Z), $x$ (Z), - теплоемкость, плотность и теплопроводность соответственно; $Q(t)$ - зависимость от времени интенсивности поглощаемого излучения, q - объемная мощность тепловыделения, k и s - показатели поглощения и рассеяния; $F^{(k)}$ - функция, определяемая скоростями конвекции в радиальном $V$ и осевом $U$ направлениях $R_{i-1}$ и $E_{i-1}$ - радиус пятна по уровню ехр $(-1)$ и облученность на оси лазерного Гауссового пучка на границе раздела с предыдущим слоем 
общей форме модели учитывают особенности распространения лазерного пучка в переднем отрезке глаза, поглощение и рассеяние излучения структурными элементами нейроэпителия и сосудистой оболочки, а также такие факторы, как наличие кровотока в хориоидее с градиентом скорости на участке от мембраны Бруха до склеры. Лазерное излучение поглощается меланопротеиновыми гранулами (МПГ) и преобразуется в тепло.

Оптические свойства интраокулярных структур в переднем отрезке глазного яблока выбраны с ориентацией на возраст пациента выше 40 лет. Концентрация пигмента в РПЭ принята равной 0,2 и характерна для человека европейского типа. Заявленная комбинированная технология лазерного лечения ЭРМ включает сочетание непрерывной лазеркоагуляции по типу «решетки» со следующими энергетическими параметрами - длина волны 577 нм, мощность 50 мВт, длительность импульса 0,05 с, диаметр пятна 100 мкм, расстояние между лазеркоагулятами 150 мкм и субпорогового микроимпульсного лазерного воздействия - длина волны 577 нм, длительность пакета 30 мс, длительность микроимпульса 50 мкс, скважность 4,7\%, частота следования микроимпульсов 1000 Гц, диаметр пятна 100 мкм, мощность 50 мВт [18]. Эти параметры использовали в качестве начальных условий для расчетов. Температурное поле в тканях хориоретинального комплекса определяли посредством численного решения двумерного уравнения теплообмена $[19,22]$. Уравнение для каждого слоя модели представлено на рис. 2. В расчете диаметр облучаемой области в плоскости пигментного эпителия принят равным 100 мкм, в соответствии с диаметром пятна. Радиальное распределение облученности считается Гауссовым. Было использовано лазерное излучение длиной волны 577 нм. С учетом возраста и обычных оптических потерь в переднем отрезке глаза мощность излучения, поглощаемая в хориоретинальном комплексе, принята равной 0,035 Вт [21, 23]. В этом случае при радиусе пучка $r=50$ мкм облученность тканей в плоскости внутренней пограничной мембраны составляет $\mathrm{E} \approx 4,5 \cdot 10^{6} \mathrm{Bт} / \mathrm{M}^{2}$. Форма импульса лазерного излучения (в уравнении она определяет функцию $Q(t)$ ) принята прямоугольной.

\section{РЕЗУЛЬТАТЫ ИССЛЕДОВАНИЯ И ОБСУЖДЕНИЕ}

Ниже представлена динамика формирования и последующей эволюции температурного поля при облучении сетчатки лазерным импульсом с приведенными параметрами. Результаты расчета распределения температуры на оси лазерного пучка ( $r=0)$ представлены на рис. 3. Кривая 1 отражает уровень нагрева тканей (функция $T(Z, r=0)) \mathrm{k}$ моменту окончания лазерного импульса. Комментируя характер этой зависимости, отметим следующее: усредненный показатель оптического поглощения РПЭ для

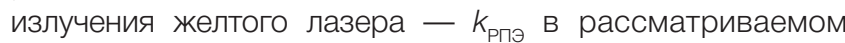
случае имеет порядок $3-10^{-4} \mathrm{M}^{-1}$. В этом случае примерно 30\% энергии падающего излучения поглощают пигментные гранулы РПЭ, 70\% распространяется далее в капиллярный слой и хориоидею, поглощается гемоглобином крови, что вызывает адекватный нагрев тканей (кривая 1, рис. 3).

В прилежащей к РПЭ области хориоидеи создается зона повышенного нагрева, превышающая температуру РПЭ. Эта область служит своеобразным буфером, обеспечивающим направленное распространение теплового фронта к внутренним слоям нейроэпителия. При этом она не только препятствует отводу тепловой энергии от РПЭ в сторону хориоидеи, но и осуществляет своеобразную «подпитку» нейроэпителия, направленного к внутренним областям. При остывании в рассматриваемых условиях тепловой фронт достигает внутренней пограничной мембраны примерно через 0,3 с после начала облучения. В дальнейшем процесс остывания продолжается несколько секунд и стимулирует фототермическую регенерацию всех структурных элементов нейроэпителия.

Отметим также, что относительно невысокий (в частности, по сравнению с ki зеленой области спектра)

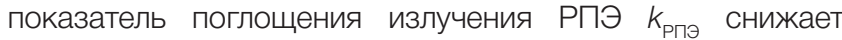
критичность лучевой стойкости тканей глазного дна к индивидуальной степени пигментации пациентов. Это качество крайне важно для современной офтальмохирургии, с учетом отсутствия поглощения желтой линии спектра макулярными пигментами [20, 21, 24].

Динамика нагрева и остывания тканей $T(t, Z, r=0)$ в отдельных слоях сетчатки вблизи оси лазерного пучка показана на рис. 4. На графике выделены области, соответствующие определенному доминирующему оптотермическому воздействию излучения на ткани сетчатки.

Показано, что импульсный нагрев в течение 0,05 с примерно на $35^{\circ} \mathrm{C}$ выше физиологической нормы приводит к термической денатурации белков РПЭ и сенсорной сетчатки $[19,25]$. Около 70\% белковых молекул подвергаются при этом необратимому воздействию. Указанное значение температуры для рассматриваемых условий называют пороговым. Повышение температуры над пороговым значением усугубляет необратимые деструктивные изменения тканей: на рис. 5 область нагрева тканей, расположенная выше пороговой температуры, определена термином «denaturation».

Импульсный нагрев тканей в интервале примерно 10-25 ${ }^{\circ} \mathrm{C}$ не вызывает необратимых изменений структуры тканей, при этом имеет место терапевтическое воздействие, включающее стимуляцию регенеративных процессов в тканях сетчатки [26]. Эта область определена на рисунке термином «Photothermal stimulation».

Для промежуточного интервала импульсного нагрева, равного 25-35 ${ }^{\circ} \mathrm{C}$, характерна конкуренция деструктивных и репаративных процессов. Любые оценки степени доминирования одного из этих процессов могут иметь не более чем оценочный характер. Математическое моделирование не обеспечивает приемлемой точности этих оценок. Указанная область названа «The staging area».

Таким образом, при выбранных энергетических режимах облучения сетчатки модель прогнозирует

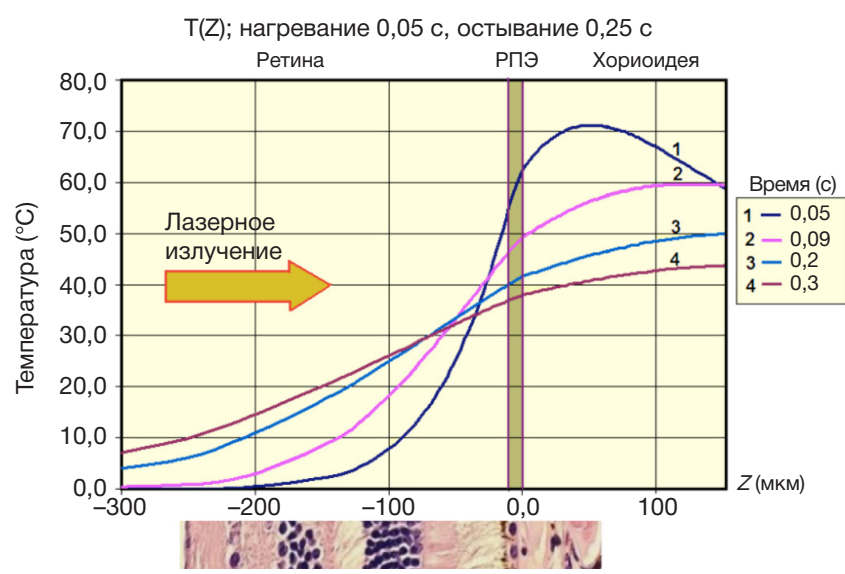

Рис. 3. Зависимость нагрева тканей сетчатки от длительности импульса Координаты $Z(r=0)$ толщины хориоретинального комплекса к моменту окончания импульса излучения, $t=0,05$ с (1) и в процессе остывания через 0,09 с (2), 0,2 c (3) и 0,3 с (4) от начала облучения 
полную денатурацию белковых структур РПЭ и локальную, полную или частичную, коагуляцию сенсорной сетчатки (кривая 1, рис. 4). Наиболее эффективное терапевтическое фототермическое действие излучения на ткани реализуется в области наружного и внутреннего ядерного слоев и захватывает частично внутренний плексиформный слой и слой ганглиозных клеток. Отметим также, что длительность терапевтического нагрева указанных областей определяет процесс остывания тканей в облучаемой области. Время остывания в рассматриваемом случае во много раз превышает длительность непосредственного лазерного воздействия и достигает нескольких секунд.

В области сетчатки, близкой к внутренней пограничной мембране и формирующейся ЭРМ, вероятность эффективной фототермической стимуляции остается конечной, но существенно снижается (кривая 5, рис. 4). Это обстоятельство практически исключает непосредственную фотостимуляцию роста патологической ЭРМ. Для демонстрации радиального распределения температуры в рассматриваемых условиях представлены изотермы для 10, 25 и $35^{\circ} \mathrm{C}$ в плоскости $r, Z$ (рис. 5). Выбранные интервалы температур соответствуют данным на рис. 3. Таким образом, уменьшение длительности импульса до 0,03 с сдвигает область эффективной фототермической стимуляции ближе к внутреннему ядерному слою. Увеличение длительности импульса до 0,07 с, наоборот, углубляет зону терапевтического нагрева, охватывает ЭРМ и может непосредственно стимулировать ее рост.

\section{Оценка термомеханического действия излучения на ткани при стимуляции в микроимпульсном режиме}

Для оценки термомеханического действия коротких импульсов лазерного излучения на биологические структуры использовали более сложный математический аппарат [27, 28]. Воздействие коротких импульсов сопровождается генерацией механических (акустических) колебаний. Для импульсов длительностью 50 мкс при мощности желтого лазера 50 мВт амплитуда механических колебаний имеет порядок десятых долей бар (1 бар ₹ 1 атм).
Порог механического (кавитационного) разрушения биоткани в этом случае имеет порядок 30-40 бар [28, 29].

Расчеты показывают, что при выбранной мощности лазера 50 мВт и длительности лазерного импульса 50 мкс нагрев на оси лазерного пучка в самой горячей точке пигментного эпителия не превышает 0,15 ${ }^{\circ} \mathrm{C}$. При частоте следования 1000 Гц следующий короткий импульс прибывает через $10^{-3}$ с (1 мс). Какой бы уровень нагрева ни был, остывание - медленный процесс. В промежутке между импульсами РПЭ полностью не остывает и, таким образом, от импульса к импульсу происходит накопление нагрева. За период 0,03 с формируется постоянная составляющая нагрева, близкая $2^{\circ} \mathrm{C}$. Пороговая температура, как сказано выше, составляет 30-35 ${ }^{\circ} \mathrm{C}$. Нагрев и остывание для всех частей сетчатки

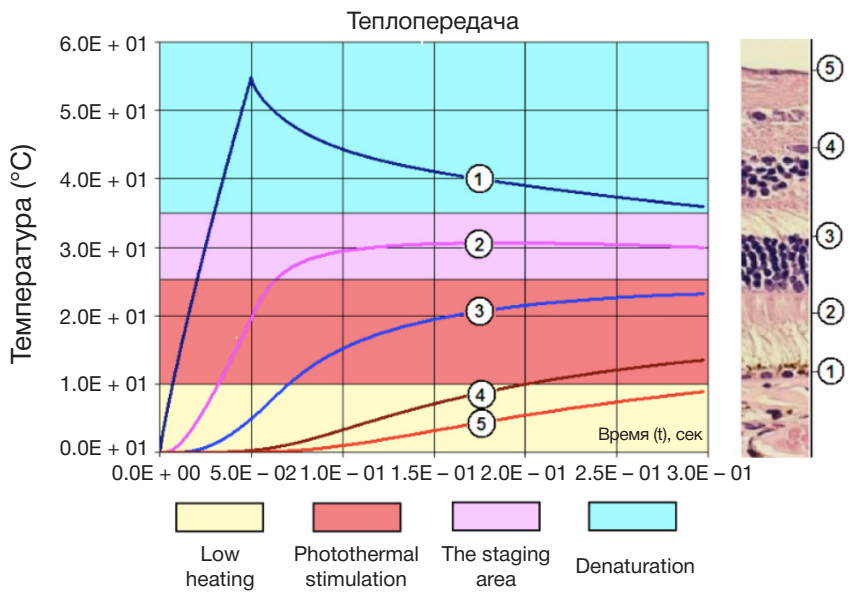

Рис. 4. Динамика нагрева и остывания $T(t, Z, r=0)$ в зонах сетчатки, соответствующих $Z_{i} .1$ - ретинально-пигментный эпителий (0,0 мкм), 2 фоторецепторный слой (60 мкм), 3 - наружный зернистый слой (110 мкм), 4 - внутренний зернистый слой (200 мкм), 5 - внутренняя пограничная мембрана (260 мкм). Синим обозначена зона необратимой денатурации белковых молекул при температуре выше $25^{\circ} \mathrm{C}$. Красным обозначена зона фототермальной стимуляции, где температура достигает диапазона от 10 до $25^{\circ} \mathrm{C}$, при данной температуре терапевтический эффект достигается, при этом необратимая денатурация практически не происходит. Промежуточная зона, обозначенная сиреневым, является зоной перехода репаративных процессов к необратимой денатурации белковых молекул

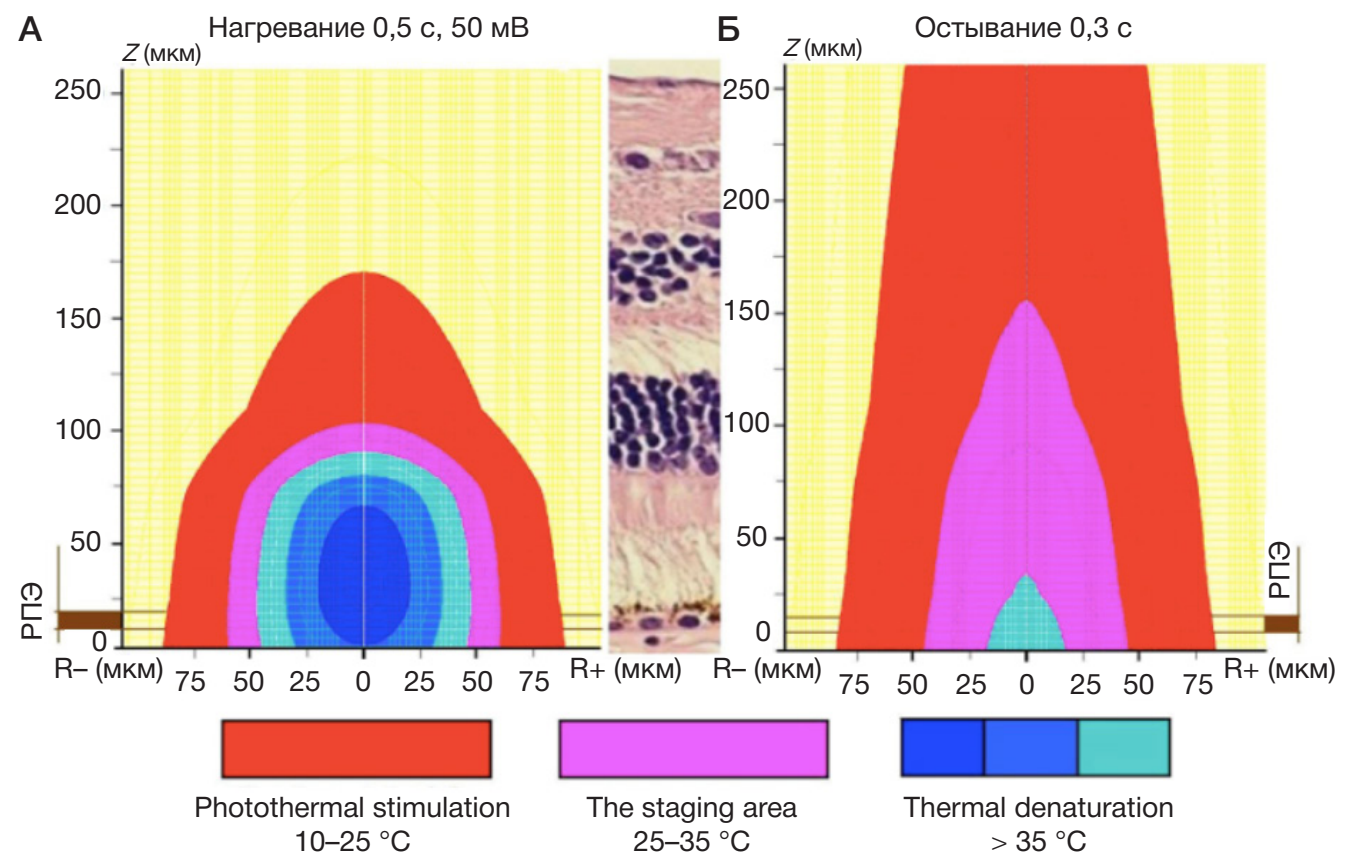

Рис. 5. Распределение уровня нагрева (А) и уровня остывания (Б) тканей сетчатки $T(r, Z)$ в сагиттальной плоскости к моменту окончания лазерного импульса при $t=0,05$ с и при остывании для $t=0,3$ с 
происходит по законам, аналогичным показанным на рис. 2-4, однако в данном случае нагрев в 20 раз ниже.

Таким образом, и термическое, и механическое действие излучения на ткани при выбранном для стимуляции режиме достаточно «легкое». Фотостимулированное нарушение нативной структуры нейроэпителия практически исключено. Терапевтический эффект обусловлен термомеханическим воздействием низкоинтенсивного излучения с указанными параметрами.

Для демонстрации эффективности и безопасности предложенной технологии приводим следующий клинический случай.

Пациент И., 68 лет. Жалобы на снижение остроты зрения и «искривления» правым глазом. При поступлении некоррегированная острота зрения (НКО3) составила 0,6, максимально коррегированная острота зрения (МКОЗ) - 1,0. При биомикроскопии: OD - оптические среды прозрачны. Диск зрительного нерва (ДЗН) бледно-розовый, границы четкие. В макулярной зоне визуализируется «целлофановая» мембрана.

Пациенту было проведено комплексное мультимодальное обследование, включающее в себя: мультиспектральное лазерное сканирование сетчатки «Multicolor», с использованием монохроматических фильтров: синего (BR; 488 нм), зеленого (GR; 515 нм) и инсрракрасного (IR; 820 нм); спектральную оптическую когерентную томографию (СОКТ), оптическую когерентную томографию ангиографию (OKTA) в режиме «En Face» с помощью «Spectralis OCT» (Heidelberg Engineering, Inc; Германия) и компьютерную микропериметрию с помощью MAIA (CenterVue; Италия).

В результате мультиспектрального исследования в режиме «Multicolor» были визуализированы очаговые желтозеленые фокусы от поверхности ЭРМ, характеризующие ее проминирование (рис. 6А). По результатам компьютерной микропериметрии в центральной зоне средняя

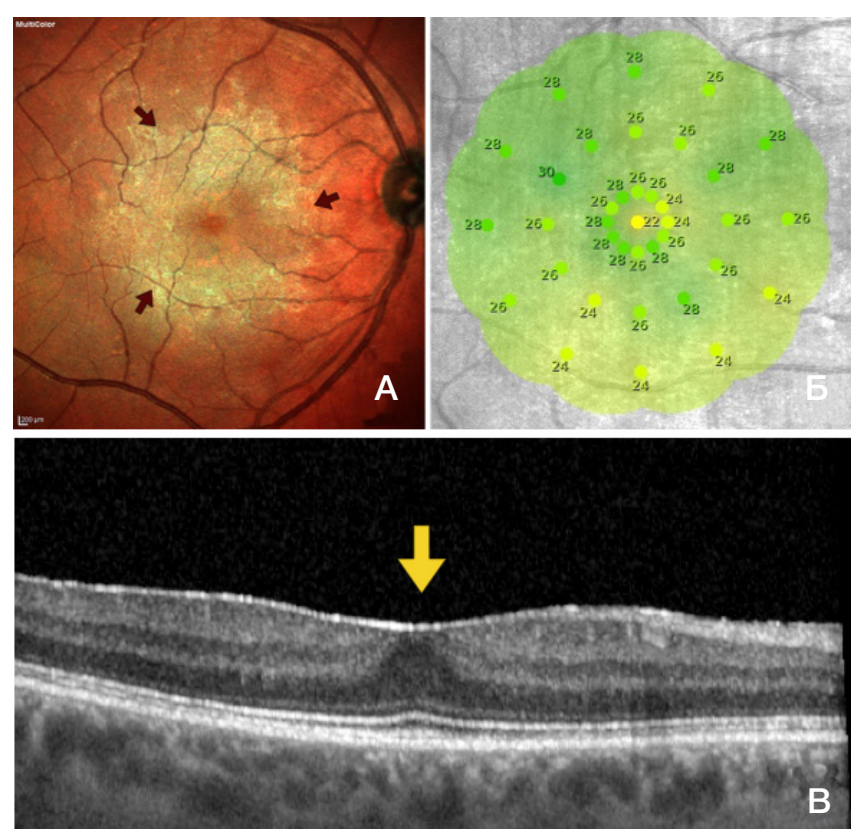

Рис. 6. Исследование глазного дна до начала лечения. Снимок глазного дна в режиме Multicolor в желто-зеленом цвете визуализируются поверхность и границы ЭРМ (красная стрелка) (А); компьютерная микропериметрия макулярной зоны: средняя величина светочувствительности - 26,3 дБ (Б) COKT: на ретинальной поверхности мембраны определяется линия гиперрефлективности, полностью слитая с внутренней пограничной мембраной; фовеолярный профиль сглажен (желтая стрелка), толщина сетчатки в центральной зоне составила 257 мкм (B) светочувствительность сетчатки составила 26,3 дБ (рис. 6Б). По данным ОКТ-томограммы, проходящей через фовеа, визуализировалась гиперрефлективная линия, плотно связанная с внутренней пограничной мембраной, при этом фовеолярный профиль был сглажен. Отмечалось увеличение
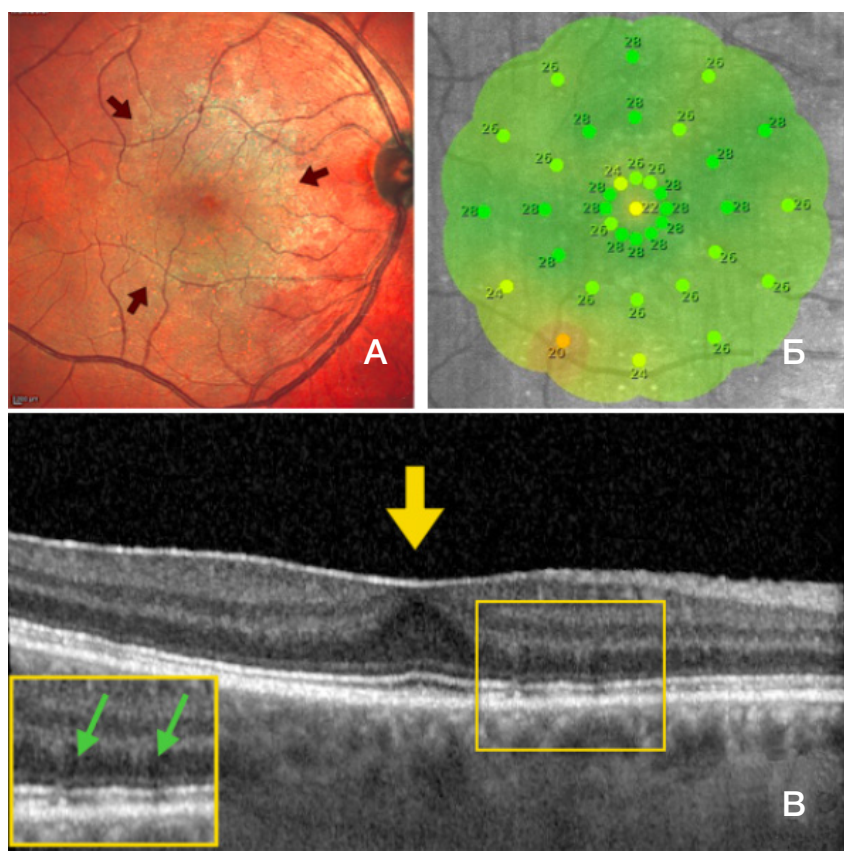

Рис. 7. Исследование глазного дна после проведения лазерной коагуляции по типу "решетки". Снимок глазного дна в режиме «Multicolor»: в макулярной зоне наблюдается снижение плотности и «стушеванность" границ ЭРМ (красная стрелка) (А); компьютерная микропериметрия макулярной зоны: средняя величина светочувствительности - 26,5 дБ (Б). СОКТ: на ретинальной поверхности мембраны определяется линия гиперрефлективности, полностью слитая с ВПМ, фовеолярный профиль сглажен (желтая стрелка), толщина сетчатки в центральной зоне незначительно снижена до 253 мкм (В). На скане ОКТ зеленой стрелкой обозначены лазеркоагуляты, архитектоника ретинальных слоев остается неизменной

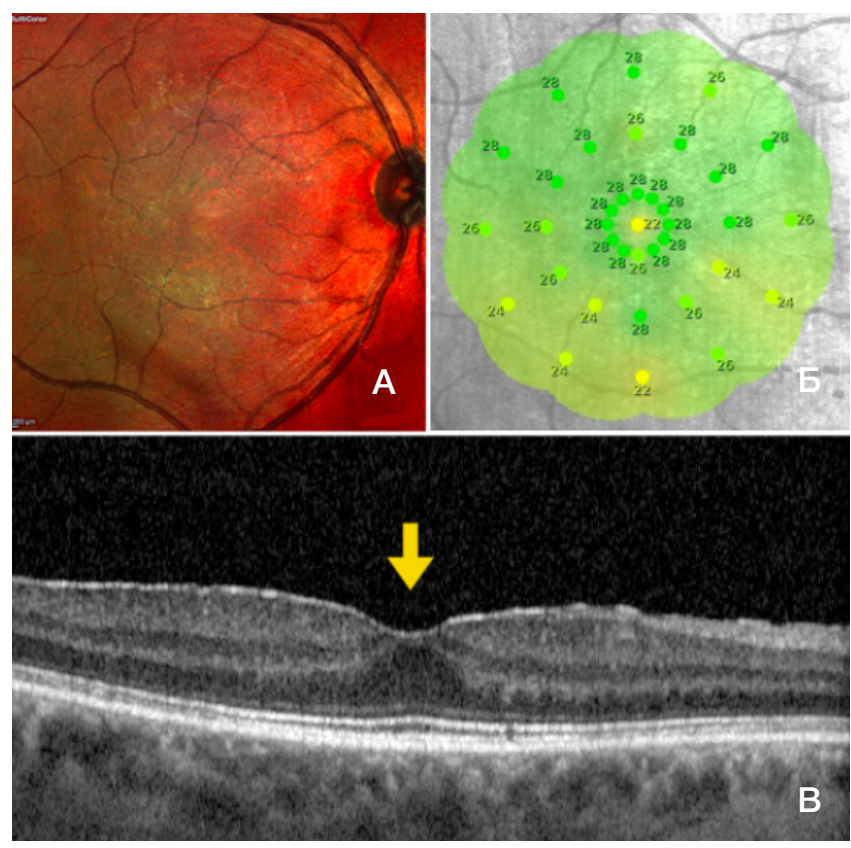

Рис. 8. Исследование глазного дна после комбинированного лазерного лечения. Снимок глазного дна в режиме "Multicolor»: визуализируется инволюция ЭРМ (А); компьютерная микропериметрия: средняя величина светочувствительности сетчатки - 26,6 дБ (Б); СОКТ: на ретинальной поверхности мембраны плотность гиперрефлективной линии уменьшилась (ЭРМ), вновь формируется фовеолярный профиль (желтая стрелка), толщина сетчатки в центральной зоне составила 246 мкм (B) 
центральной толщины сетчатки до 257 мкм. Наружная пограничная мембрана, линия сочленения наружных и внутренних сегментов фоторецепторов, комплекс пигментного эпителия-хориокапилляров и хориоидея не изменены (рис. 6В).

На основании проведенного офтальмологического обследования пациенту был поставлен диагноз: OD Эпиретинальный фиброз, 0-1 стадия. Предложено проведение лазерного лечения по комбинированной технологии, включающей в себя непрерывное лазерное воздействие по типу «решетки» длиной волны 577 нм и субпороговое микроимпульсное лазерное воздействие длиной волны 577 нм (3 сеанса с периодичностью месяц).

На первом этапе лечения проводили непрерывную лазерную коагуляцию сетчатки по типу «решетки», исключая аваскулярную зону, со следующими энергетическими параметрами: длина волны - 577 нм, мощность - 50 мВт, длительность импульса - 0,05 с, диаметр пятна - 100 мкм, расстояние между лазеркоагулятами - 150 мкм. Через 2 недели проведено контрольное офтальмологическое исследование: ОD НКО3 - 0,7; МКОЗ - 1,0. По данным мультиспектрального исследования в режиме «Multicolor» в центральной зоне наблюдали снижение плотности и «стушеванность» границ ЭРМ, по всей поверхности мембраны, исключая аваскулярную зону, были отмечены лазерные коагуляты (рис. 7А). По данным компьютерной микропериметрии средняя светочувствительность сетчатки составила 26,5 дБ (рис. 7Б). По данным COKT: фовеолярный профиль сглажен, видна гиперрефлективная линия, плотно прилежащая к ретинальной поверхности (ЭРМ). Отмечено снижение толщины сетчатки в центральной зоне до 253 мкм. Наружная пограничная мембрана, линия сочленения наружных и внутренних сегментов фоторецепторов, комплекс пигментного эпителия хориокапилляров, хориоидея не изменены (рис. 7B)

После проведения трех сеансов субпорогового микроимпульсного лазерного воздействия с периодичностью раз в месяц, на контрольном осмотре через 6 месяцев выполнено комплексное офтальмологическое обследование: НКОЗ составило 0,9, МКОЗ - 1,0. По данным мультиспектрального исследования в режиме «Multicolor», в центральной зоне визуализируется инволюция ЭРМ (рис. 8А). По данным компьютерной микропериметрии, средняя светочувствительность сетчатки составила 26,6 дБ (рис. 8Б). По данным СОКТ, отмечается формирование фовеолярного профиля, центральная толщина сетчатки снижена до 246 мкм. Наружная пограничная мембрана, линия сочленения наружных и внутренних сегментов фоторецепторов, комплекс пигментного эпителия хориокапилляров, хориоидея не изменены (рис. 8В). На ретинальной томограмме в послеоперационном периоде отмечена корреляция зон коагуляции с зонами фототермической стимуляции, отраженной на рис. 3 и 4.

\section{ВЫВОДЫ}

Разработана новая технология комбинированного лазерного лечения ЭРМ при начальных стадиях ее формирования. С использованием методов математического моделирования проведены углубленные исследования динамики термомеханического действия лазерного излучения на структурные элементы нейроэпителия в процессе лечебного воздействия на ЭРМ. По результатам исследований показаны основные механизмы лечебного эффекта комбинированного лазерного воздействия при ЭРМ.

\section{Литература}

1. Leask $A$, Abraham D. TGF- $\beta$ signaling and the fibrotic response. The FASEB Journal. 2004; 18 (7): 816-27.

2. Качалина Г. Ф., Касмынина Т. А., Иванова Е. В., Куранова О. И. Лазерное лечение транссудативной макулопатии, вызванной наличием эпиретинальной мембраны. Современные технологии лечения витреоретинальной патологии. В сборнике тезисов. ФГБУ «МНТК «Микрохирургия глаза». 2012; 94-6.

3. Patronas M, Kroll A, Lou P, Ryan E. A Review of Vitreoretina Interface Pathology. International Ophthalmology Clinics. 2009; 49 (1): 133-43.

4. Пономерёва Е. Н., Казарян А. А. Структурно-функциональные особенности макулярной зоны сетчатки при идиопатической эпиретинальной мембране. Российский офттальмологический журнал. 2013; (2): 66-9.

5. Guidry C. The role of Müller cells in fibrocontractive retinal disorders. Progress in Retinal and Eye Research. 2005; 24 (1): 75-86.

6. Harada C, Mitamura Y, Harada T. The role of cytokines and trophic factors in epiretinal membranes: Involvement of signal transduction in glial cells. Progress in Retinal and Eye Research. 2006; 25 (2): 149-64.

7. Zhao F, Gandorfer A, Haritoglou C, Scheler R, Schaumberger M, Kampik A, et al. Epiretinal Cell Proliferation in Macular Pucker and Vitreomacular Traction Syndrome. Retina. 2013; 33 (1): 77-88.

8. Joshi M, Agrawal S, Christoforidis J. Inflammatory Mechanisms of Idiopathic Epiretinal Membrane Formation. Mediators of Inflammation. 2013; (2013): 1-6.

9. Hinz B, Phan SH, Thannickal VJ, et al. The myofibroblast: one function, multiple origins. Am J Pathol. 2007; (170): 1807-16.

10. Захаров В. Д., Борзенок С. А., Горшком И. М., Колесник С. В.,
Колесник А. И., Миридонова А. В. Этиопатогенетические аспекты и роль структур витреоретинального интерфейса в формировании идиопатических эпиретинальных мембран. Практическая медицина. 2018; (114): 71-6.

11. Качалина Г. Ф., Дога А. В., Касмынина Т. А., Куранова О. И. Эпиретинальный фиброз: патогенез, исходы, способы лечения. Офтальмохирургия. 2013; (4): 108-10.

12. Куранова О. И. Изучение эффективности микроимпульсного лазерного воздействия длиной волны 577 нм при макулярном отеке после хирургического удаления идиопатической эпиретинальной мембраны [диссертация]. 2014.

13. Bu S, Kuijer R, Li X, Hooymans J, Los L. Idiopathic epiretinal membrane. Retina. 2014; 34 (12): 2317-35.

14. Большунов А. В. Вопросы лазерной осртальмологии. М., 2013; 316 с.

15. Краснов М. М., Сапрыкин П. И., Доронин П. П., Никольская Г. М., Акопян В. С., Мамедов Н. Г. Электронно-микроскопическое изучение тканей глазного дна при лазеркоагуляции. Вестник офтальмологии. 1973; (2): 9-12.

16. Федорук Н. А., Федоров А. А., Большунов А. В. Морфологические и гистохимические особенности субпорогового лазерного воздействия на структуры хориоретинального комплекса. Вестник офтальмологии. 2013; (5): 73-81.

17. Желтов Г. И., Романов Г. С., Романов О. Г., Иванова Е. В. Селективное действие лазерных импульсов на ретинальный пигментный эпителий. Физические основы. Новое в офтальмологии. 2012; (3): 37-43.

18. Тахчиди Х. П., Качалина Г. Ф., Касмынина Т. А., Тебина Е. П. Способ комбинированного лазерного лечения начальной стадии эпиретинального фиброза. Патент РФ №2634684. 02.11.2017. 
19. Желтов Г. И. Воздействие интенсивного оптического излучения на ткани глаз: исследования и приложения [диссертация]. 1996.

20. Желтов Г. И. Биофизика деструктивного действия надпорогового лазерного излучения на ткани глазного дна. II Всероссийский семинар: «МАКУЛА 2006». Доклад в сборнике материалов конференции. 2006; 71-85.

21. Jacobs S. Safety with Lasers and Other Optical Sources, by D. Sliney and M. Wolbarsht. Medical Physics. 1981; 8 (5): 725-6.

22. Карслоу Г., Егер Д. Теплопроводность твердых тел. М. Наука, 1964; 488.

23. Линник Л.А., ЖелтовГ.И., Глазков В. Н. ПухликЕ. С., ПриваловА. П. Изменение энергетических порогов лазерокоагуляции тканей сетчатки с возрастом больных. Офтальмологический журнал. 1988; 6 (302), 355-8.

24. Желтов Г. И. Действие надпорогового лазерного излучения на ткани глазного дна. Офттальмология в Беларуси. 2009; 3 (03): 24-40.
25. Barnes FS. Bological Damage Resulting from Thermal Pulses. In: Wolbarsht ML, Ed. Laser Application in Medicine and Biology. Ntw York: Plenum Press, 1984; 205-22.

26. Клепинина О. Б. Субпороговое микроимпульсное лазерное воздействие длиной волны 577 нм при лечении центральной серозной хориоретинопатии. Тамбов, 2014; 61.

27. Romanov OG, Romanov GS, Zheltov Gl. Numerical modelling of photo-thermal and photo-mechanical effects in absorbing biological structures under action of short laser pulses Proceedings of SPIE. 2013; (8803). DOI: 10.1117/12.2032462.

28. Zheltov G, Lisinetskii V, Grabtchikov A, Orlovich V. Low-threshold cavitation in water using IR laser pulse trains. Applied Optics. 2008; 47 (20): 3549-54.

29. Oraevsky A, Jacques S, Esenaliev R, Tittel F. Pulsed laser ablation of soft tissues, gels, and aqueous solutions at temperatures below $100{ }^{\circ} \mathrm{C}$. Lasers in Surgery and Medicine. 1996; 18 (3): 231-40.

\section{References}

1. Leask A, Abraham D. TGF- $\beta$ signaling and the fibrotic response The FASEB Journal. 2004; 18 (7): 816-27.

2. Kachalina GF, Kasminina TA, Ivanova EV, Kuranova OI. Lase treatment of transudative maculopathy caused by the epiretinal membrane. Modern technologies of treatment of vitreoretinal pathology. S. Fyodorov Eye Microsurgery Federal State Institution. 2012; 94-6.

3. Patronas M, Kroll A, Lou P, Ryan E. a Review of Vitreoretinal Interface Pathology. International Ophthalmology Clinics. 2009; 49 (1): 133-43

4. Ponomareva EN, Kazaryan AA. The electroretinogram and the pattern of optical coherence tomography in patients with idiopathic epiretinal membrane. Russian Ophthalmological Journal. 2013; (2): 66-9.

5. Guidry C. The role of Müller cells in fibrocontractive retinal disorders. Progress in Retinal and Eye Research. 2005; 24 (1): 75-86.

6. Harada C, Mitamura $Y$, Harada T. The role of cytokines and trophic factors in epiretinal membranes: Involvement of signa transduction in glial cells. Progress in Retinal and Eye Research. 2006; 25 (2): 149-64.

7. Zhao F, Gandorfer A, Haritoglou C, Scheler R, Schaumberger M, Kampik a et al. Epiretinal Cell Proliferation in Macular Pucker and Vitreomacular Traction Syndrome. Retina. 2013; 33 (1): 77-88.

8. Joshi M, Agrawal S, Christoforidis J. Inflammatory Mechanisms of Idiopathic Epiretinal Membrane Formation. Mediators of Inflammation. 2013; (2013): 1-6.

9. Hinz B, Phan SH, Thannickal VJ, et al. The myofibroblast: one function, multiple origins. Am J Pathol. 2007; (170): 1807-16.

10. Zakharov VD, Borzenok SA, Gorshkov IM, Kolesnik SV, Kolesnik AI, Miridonova AV. Etiological and pathogenetic aspects and role of vitreoretinal interface structures in idiopathic epiretinal membranes formation. Practical medicine. 2018; (114): 71-76.

11. Kachalina GF, Doga AV, Kasmynina TA, Kuranova OI. Epiretinal fibrosis: pathogenesis, outcomes, treatment methods. Ophthalmosurgery 2013; 4: 108-10.

12. Kuranova OI. The study of the effectiveness of micropulse laser irradiation with a wavelength of $577 \mathrm{~nm}$ in macular edema after surgical removal of idiopathic epiretinal membrane [dissertation]. 2014.

13. Bu S, Kuijer R, Li X, Hooymans J, Los L. Idiopathic epiretinal membrane. Retina. 2014; 34 (12): 2317-35.

14. Bolshunov AV. Questions of laser ophthalmology. M., 2013; 316.

15. Krasnov MM, Saprykin PI, Doronin PP, Nikolskaya GM, Akopyan VS,

Mamedov NG. Electron-microscopic examination of the fundus tissue during laser coagulation. Bulletin of Ophthalmology. 1973; (2): 9-12.

16. Fedoruk NA, Fedorov AA, Bol'shunov AV. Morphological and histochemical effects of subthreshold laser therapy on the chorioretinal complex/ Bulletin of Ophthalmology. 2013; (5): 73-81.

17. Zheltov GI, Romanov GS, Romanov OG, Ivanova EV. Selective effect of laser pulses on the retinal pigment epithelium. Physical basis. New in ophthalmology. 2012; (3): 37-43.

18. Tahchidi HP, Kachalina GF, Kasmynina TA, Tebina EP. The method of combined laser treatment of the initial stage of epiretinal fibrosis RF № 2634684. 02.11.2017.

19. Zheltov Gl. Effect of intense optical radiation on eye tissue: research and applications. Extended abstract of candidate's thesis [dissertation]. 1996.

20. Zheltov Gl. Biophysics of the destructive action of the abovethreshold laser radiation on the fundus tissue. II All Russian seminar: "MAKULA 2006". Report in the conference proceedings. 2006; 71-85.

21. Jacobs S. Safety with Lasers and Other Optical Sources, by D. Sliney and M. Wolbarsht. Medical Physics. 1981; 8 (5): 725-6.

22. Karslow G, Eger D. Thermal conductivity of solids. M.: Science, 1964; 488.

23. Linnik LA, Zheltov Gl, Glazkov VN, Puhlik ES, Privalov AP. Change of energy thresholds of laser coagulation of retinal tissues with the age of patients. Ophthalmological journal. 1988; 6 (302): 355-8.

24. Zheltov Gl. Effects of above-threshold laser radiation on the fundus tissue. Ophthalmology in Belarus. 2009; 3 (03): 24-40.

25. Barnes FS. Bological Damage Resulting from Thermal Pulses. In: Wolbarsht ML, Ed. Laser Application in Medicine and Biology. Ntw York: Plenum Press, 1984; 205-22.

26. Klepinina OB Subthreshold micropulse laser treatment with a wavelength of $577 \mathrm{~nm}$ in the treatment of central serous chorioretinopathy.Tambov, 2014; 61.

27. Romanov OG, Romanov GS, Zheltov Gl. Numerical modelling of photo-thermal and photo-mechanical effects in absorbing biological structures under action of short laser pulses Proceedings of SPIE. 2013; (8803). DOI: 10.1117/12.2032462

28. Zheltov G, Lisinetskii V, Grabtchikov A, Orlovich V. Low-threshold cavitation in water using IR laser pulse trains. Applied Optics. 2008; 47 (20): 3549-54.

29. Oraevsky A, Jacques S, Esenaliev R, Tittel F. Pulsed laser ablation of soft tissues, gels, and aqueous solutions at temperatures below $100^{\circ} \mathrm{C}$. Lasers in Surgery and Medicine. 1996; 18 (3): 231-40. 